\title{
Original Research \\ The impact of pharmaceutical care on patients with hypertension and their pharmacists
}

\author{
Agnieszka SKOWRON, Sebastian POLAK, Jerzy BRANDYS \\ Received (first version): $17-$ Dec-2010 $\quad$ Accepted: 15-Jun-2011
}

\begin{abstract}
${ }^{*}$
Objective: The purpose of the study was to assess the influence of pharmaceutical care on patients' knowledge, quality of life and blood pressure and to determine whether new type of pharmaceutical services changes the pharmacists' satisfaction and knowledge.

Methods: Community pharmacies were randomly assigned to study and control group and pharmacists from both groups included patients with hypertension, who meet inclusion and exclusion criteria. Study group provided the pharmaceutical care (education, pharmacotherapy monitoring, detecting and solving drug related problems) for their patients, while the control group provided the standard pharmaceutical services (dispensing medicines with or without counseling). At the beginning and the end of the study pharmacists and patients filled in the knowledge test. Pharmacists fulfilled also satisfaction questionnaire.

Results: Survey data were collected from 28 and 56 patients from community pharmacies in study and control group respectively. At the last meeting the normal blood pressure achieved $79 \%$ and $55 \%$ patients in study and control group, respectively $(p>0,05)$. The pharmaceutical care improved patients' knowledge about disease. Pharmacists from study group, who provided pharmaceutical care, had higher level of pharmacotherapy knowledge and professional satisfaction than the control group.

Conclusion: Implementation of pharmaceutical care into the pharmacy practice benefits both, patients and pharmacists.
\end{abstract}

Keywords: Hypertension. Medication Therapy Management. Community Pharmacy Services. Poland.

\footnotetext{
*Agnieszka SKOWRON. PhD. Assistant Professor. Jagiellonian University, School of Medicine, Faculty of Pharmacy, Department of Pharmacoepidemiology and Pharmacoeconomics, Krakow (Poland).

Sebastian POLAK. PhD. Assistant Professor. Jagiellonian University, School of Medicine, Faculty of Pharmacy, Department of Pharmacoepidemiology and Pharmacoeconomics, Krakow (Poland). Jerzy BRANDYS. Professor. University Professor. Jagiellonian University, School of Medicine, Faculty of Pharmacy, Department of Pharmacoepidemiology and Pharmacoeconomics, Krakow (Poland).
}

\author{
IMPACTO DE LA ATENCIÓN \\ FARMACÉUTICA EN PACIENTES CON \\ HIPERTENSIÓN Y SUS FARMACÉUTICOS
}

\section{RESUMEN}

Objetivo: el propósito de este estudio fue evaluar la influencia de la atención farmacéutica sobre el conocimiento de los pacientes, la calidad de vida y la presión sanguínea, y determinar si un nuevo tipo de servicios farmacéuticos modifica la satisfacción del farmacéutico y el conocimiento.

Métodos: Se asigné aleatoriamente farmacias comunitarias a grupos estudio y control, y los farmacéuticos de ambos grupos incluyeron pacientes con hipertensión que cumplían los criterios de inclusión y exclusión. El grupo estudio se proporcionó atención farmacéutica (educación, seguimiento farmacoterapéutico, detección y resolución de problemas relacionados con medicamentos) a sus pacientes, mientras que el grupo control proporcionó los servicios farmacéuticos estándar (dispensación de medicamentos con o sin consejo). Al principio y al final del estudio los pacientes rellenaron un test de conocimientos. Los farmacéuticos también rellenaron un cuestionario de satisfacción. Resultados: Se recogieron datos de 28 y 56 pacientes de farmacias comunitarias de los grupos estudio y control, respectivamente. En el último encuentro, se había alcanzado la presión arterial normal en el $79 \%$ y $55 \%$ de los pacientes en los grupos de estudio y control, respectivamente $(p<0,005)$. La atención farmacéutica mejoró el conocimiento de los pacientes sobre su enfermedad. Los farmacéuticos del grupo estudio, que proporcionaron atención farmacéutica, tenían niveles más altos de conocimiento de la farmacoterapia y satisfacción profesional que los del grupo control.

Conclusión: La implantación de la atención farmacéutica en la práctica farmacéutica beneficia tanto a los pacientes como a los farmacéuticos.

Palabras clave: Hipertensión. Gestion de la Medicación. Servicios de Farmacias comunitarias. Polonia.

\section{INTRODUCTION}

Both patient-related factors (social-economic status or non-adherence) and factors related to health care system and medical staff (for example, lack of access to medical care) is listed within causes for lack of effectiveness of anti-hypertensive therapy. Effective communication between patient and 
members of medical team and appropriate amount of time and resources allocated for patient may increase effective treatment. ${ }^{1-6}$ Cooperation between physicians, pharmacist and other medical personnel, as well as encouragement of patient to systematic control of blood pressure results in effectiveness improvement of hypertension pharmacotherapy. ${ }^{7-12}$ Previous studies have demonstrated that involvement of pharmacists in taking care of patients with hypertension can improve their blood pressure and increase patients' quality of life. $^{13-22}$

Community pharmacists in Poland have not yet implemented the pharmaceutical care into their practice. The health care system in Poland expects pharmacists only to dispense medication according to physicians' prescription, pharmacists are not obliged to educate patient or monitor effectiveness or safety of their pharmacotherapy.

We conduct the first in Poland intervention study to assess whether pharmaceutical care as defined by Hepler and Strand ${ }^{23}$ may improve the effectiveness of hypertensive therapy. Additional aim of the study was to evaluate the impact of pharmaceutical care on pharmacists' professional satisfaction and their knowledge of pharmacotherapy of hypertension.

\section{METHODS}

Random study with pharmacists from Krakow (Poland) and surroundings were carried out. Information about the study and invitation for pharmacists were done during their quarterly meetings organized by Regional Pharmaceutical Chamber in Krakow. As many as 95 pharmacists from 55 community pharmacies $(29$ community pharmacies and 61 pharmacists from Krakow and 26 community pharmacies and 34 pharmacists from Krakow surroundings) signed up to participate in the study. Randomization of community pharmacies to control and study group was done by generation of random numbers by computer software. The study and the control group consisted of 28 community pharmacies (44 pharmacists) and 27 community pharmacies (51 pharmacists), respectively. After randomization, the initial meeting was carried out separately for the study and the control group. The aim of the initial meeting was to introduce the rules of the project and to do the initial evaluation of knowledge and professional satisfaction of pharmacists. Then, the cycle of trainings was carried out (three 5-hour trainings) in October and November (2004) only for the study group. These trainings included detection, classification and monitoring of drug related problems, pathophysiology of hypertension, risk factors and life style factors influencing the disease, and rules of pharmacotherapy of hypertension. Trainers and lecturers were researchers (pharmacists) and physicians (specialists in arterial hypertension and cardiology). At the final meeting in June 2006 pharmacists from study and control group once again filled in the knowledge test and professional satisfaction questionnaire. The pharmacists from control group received the identical training cycle (three 5-hour trainings) as study group after the final meeting. Pharmacists in Poland are obliged to get 100 scores (every 5 years) to maintain their professional pharmacy license. They may get scores for participation in the professional trainings carried out by institutions accredited by governmental agency. In our study pharmacists in the control group got 10 scores and pharmacists in the study group got 15 scores.

After initial meeting and training for the study group, pharmacists from both groups started enrolling patients into the project. Men and women age $\geq 18$ years with hypertension, pharmacologically treated for at least 6 months, who are able to keep moving independently and contact with surroundings were included. Subjects were excluded from the study if they had cardiovascular incident (stroke, heart attack) within the last 6 months or a history of diabetes, asthma, chronic obstructive pulmonary disease (COPD), mental disease (depression, schizophrenia), or they are unable to contact with pharmacists independently. The study was approved by local ethical board and all patients signed out consent form.

According to pharmacists from the study group, at least 12 meetings from November (2004) to January (2006) should be done during which a blood pressure should be measured using sphygmomanometer. In addition, drug related problems should be detected and solved and patient should be educated about pathophysiology, risk factors, treatment and style of life with hypertension as well as unassisted blood pressure measurement. During the first and the last meeting in the community pharmacy, patient had to fill out questionnaire evaluating his/her knowledge about hypertension. Besides, in the last meeting, he/she had to fill out questionnaire (SF-36) about his/her quality of life. ${ }^{24,25}$ Pharmacists' actions were recorded using Microsoft Access or standard paper forms. All needed items were provided free-ofcharge by researchers' team.

Pharmacists from the control group met their patients included into the study only two times between November (2004) and January (2006), at least 14 months interval between this two meetings should be kept. At each meeting patients had to fulfill questionnaire evaluating his/her knowledge about hypertension and pharmacist collected information about diagnosed diseases, used medications and results of the blood pressure measurement. On the last meeting patients had to fill out additionally the quality of life questionnaire. Pharmacists from the control group did not do any additional services for patients included into the study, so they did not monitor the pharmacotherapy and did not educate the patients. Medical history of patients was documented only in paper forms prepared for the program.

The researchers' team responsible for coordination of this project did not interfere in any way with the pharmacists' actions during this program; however, the website was prepared, its role was to facilitate exchange of information between pharmacists. Pharmacists were also informed about the possibility of consulting with the researchers team 
Skowron A, Polak S, Brandys J. The impact of pharmaceutical care on patients with hypertension and their pharmacists. Pharmacy Practice (Internet) 2011 Apr-Jun;9(2):110-115.

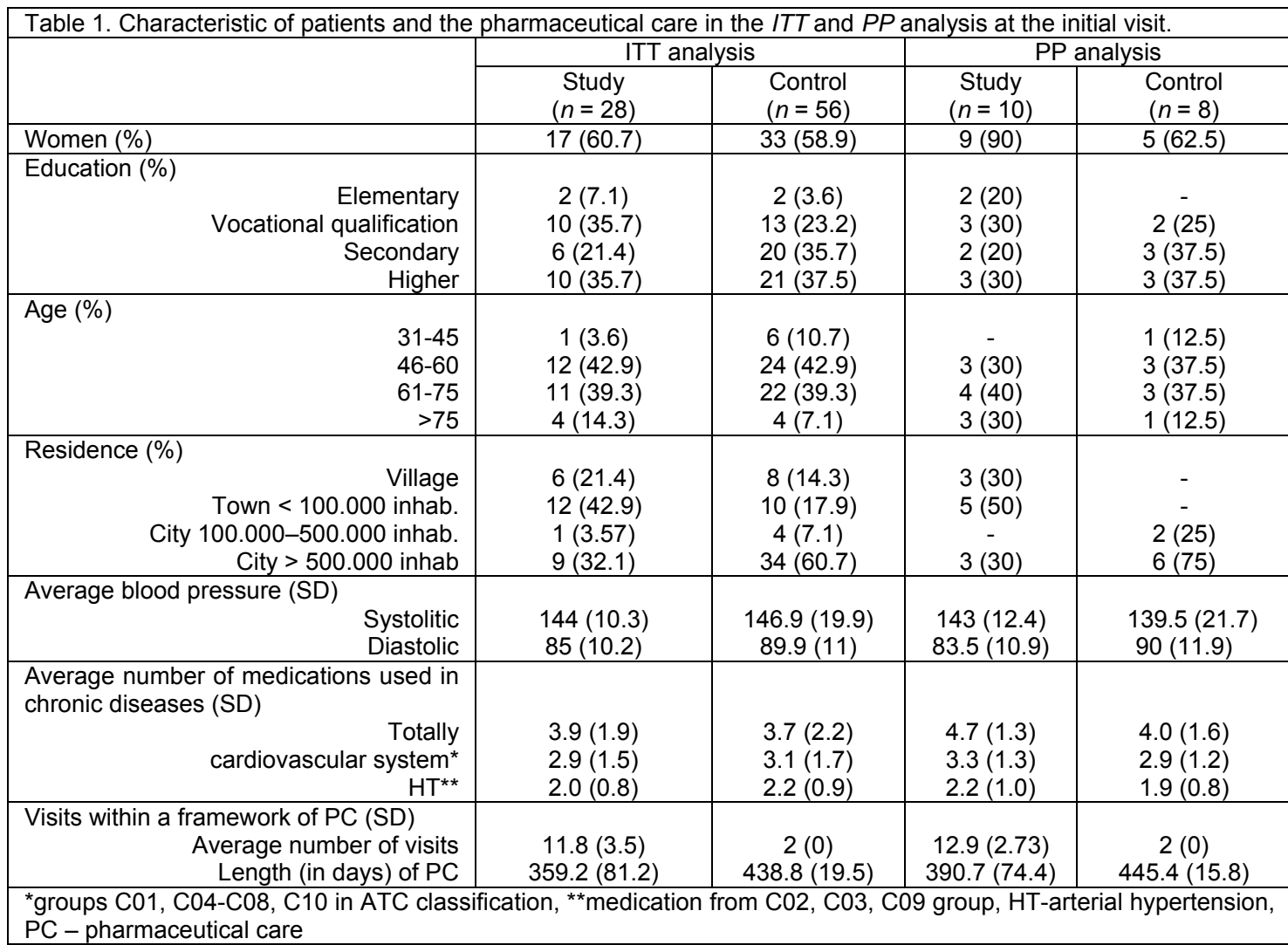

by e-mail, phone or personally during the entire period of project duration. The data recorded by Microsoft Access (only from study group) and in paper form (both, study and control group) were collected by researchers team from February to April 2006. The records contained data on patients' health condition, fulfilled questionnaires, DRPs indicated by pharmacists, actions made by pharmacists to solve DRP and copies of education leaflets prepared by pharmacists for their patients.

Statistical analysis. Continuous data were described by mean (standard deviation) and were compared unpaired t-tests for between group analyses. The Mann-Whitney $U$ test was used for between group comparisons for variables that were not normally distributed. Categorical data were described by percentage and were compared by chi-square test with continuity correction or Fisher's exact test, as appropriate. The significance level was at 0.05 . All analyses were completed using Statistica version 9 .

\section{RESULTS}

From all community pharmacies randomized to control and study group only 20 community pharmacies from the study group (35 pharmacists) and 19 community pharmacies from the control group (39 pharmacists) included 70 and 123 patients, respectively. Six community pharmacies (15 pharmacists) from study group and three (10 pharmacists) from control group resigned before the first meeting with patients. Therefore the first meeting was carried on for 34 patient and 84 in study and control group, respectively. Afterward six patients in study group and 28 in control group resigned, two were moved (from control group) away and the others declared lack of time to visit community pharmacy or lack of interest in further participation in the program. The analysis of results was conducted according to Intention of treat (ITT) and Per Protocol (PP) methods. Data of all patients who had at least two visits and filled out at the first and last meeting the knowledge questionnaires were included to the ITT analysis. In addition, pharmacists that took care of those patients filled out one of the questionnaires were evaluated. Data of patients who had planned number of visits $(\geq 12$ in the study group and 2 in the control group) were evaluated in PP analysis only if their pharmacists fulfilled two times the knowledge and satisfaction questionnaire.

The control and study group differed in terms of education, age and place of residence. No difference was detected in the number of dispensed anti-hypertension medications and other medications dispensed in cardiovascular diseases at the time of enrollment into the study. Average patient covered by pharmaceutical care had around $11.8(\mathrm{SD}=3.5)$ visits in a community pharmacy during 359 ( $S D=81.2$ ) days (ITT analysis). In a group which finished the program (PP analysis), 12.9 (SD=2.7) visits was recorded during 391 $(S D=74.4)$ days of program duration. In the control group, the time between the first and the last visit was around $439(\mathrm{SD}=19.5)$ days (ITT analysis) or 445 (SD=15.8) days (PP analysis). A detailed information about characteristic of patients included to ITT and PP analysis is presented in Table 1.

At the last visit it was observed that patients from the study group have been taken one antihypertensive and two cardiovascular diseases medications more than they declared at the initial 


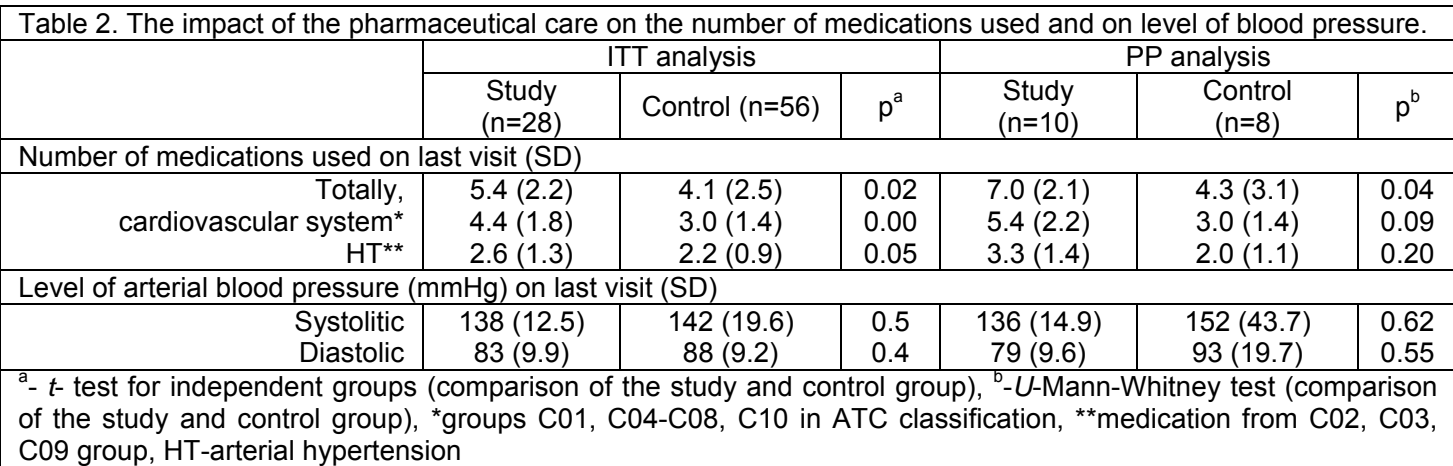

visit. The number of dispensed medications did not change in the control group. Detailed data are presented in Table 2. Increased number of dispensed medications did not have any effect on therapy efficacy, which was measured as an average decrease in arterial blood pressure at the end of pharmaceutical care. However, at the end of the program it was demonstrated that the normal blood pressure was in 22 out of 28 patients $(79 \%)$ in the study group, and in 31 out of 56 patients $(55 \%)$ in the control group (chi-square Pearson test, $\mathrm{p}<0.05$ ) according to ITT analysis. Among the patients included in the full pharmaceutical care program (PP analysis), the normal blood pressure was recorded in 8 out of 10 patients $(80 \%)$ from the study group, and in 6 out of 8 patients $(75 \%)$ in the control group $(p=0.80)$.

Before the beginning of the study, the level of patient knowledge regarding hypertension in the study and the control group was similar, 24.8 $(S D=5.3)$ and $26.1(S D=4.5)$ points, respectively. No higher level of knowledge in general were observed in patients of the study and the control group, 28.3 $(S D=4.2)$ and $27(S D=4.5)$ points, respectively $(p=$ 0.2 ) at the end of the study. However, pharmaceutical care increased the knowledge about the disease (ITT analysis) in the study group it was 8.1 points $(S D=2.2)$ in comparison with 6.8 $(S D=2.4)$ points in the control group (t-test, $p<$ 0.05) (Table 3).

Analysis of health-related quality of life was done by filling out the SF-36 questionnaire when the study was finished. No effect of pharmaceutical care on improvement of quality of life was observed in ITT or PP analysis.

Additionally, impact of pharmaceutical care on knowledge and professional satisfaction of pharmacists were evaluated. An increase of knowledge in relation to therapy and pathology of hypertension was observed during both ITT and PP analysis in pharmacists from the study group.
During PP analysis, the improvement in knowledge was observed in all pharmacists $(100 \%)$ in the study group, whereas only one person (12.5\%) demonstrated better knowledge in the control group (chi-square Pearson test, $\mathrm{p}<0.05$ ). Individual data are presented in Table 4.

\section{DISCUSSION}

Our study had limitation and the results obtained have to be considered with these limitations. The randomization of community pharmacies to the study and control group were done due to avoid unintended increase in quality of standard pharmaceutical services, but it might have influenced the number and characteristic of patients enrolled into the study and control group. Assignment to the study group could be the reason for resignation from the study of a large part of community pharmacies. Despite this limitation we did not observe the differences in characteristic of patients included in study and control group.

The significant difference in knowledge about disease between study and control group was observed at the end of the study. Subjects in the study group at the end of study were receiving higher number of medications comparing to the control group. At the end of the program more patients in study group (79\%) then in control group $(55 \%)$ obtained at least high regular level of blood pressure. $^{26}$

In agreement with Hunt et al. study ${ }^{10}$, it was demonstrated that inclusion of pharmacist to monitor pharmacotherapy and provide pharmaceutical care resulted in increase in number of used antihypertensive and cardiovascular disease medications.

Pharmaceutical care had beneficial effect on therapy results, because at the last meeting normal values of arterial blood pressure $(\leq 140 / 90 \mathrm{mmHg})$ achieved $79 \%$ of patients from the study group had

\begin{tabular}{|c|c|c|c|c|c|c|}
\hline & \multicolumn{3}{|c|}{ ITT analysis } & \multicolumn{3}{|c|}{ PP analysis } \\
\hline & $\begin{array}{c}\text { Study } \\
(n=28) \\
\text { Mean (SD) }\end{array}$ & $\begin{array}{c}\text { Control } \\
(n=56) \\
\text { Mean (SD) } \\
\end{array}$ & $p^{a}$ & $\begin{array}{c}\text { Study } \\
(n=10) \\
\text { Mean (SD) }\end{array}$ & $\begin{array}{c}\text { Control } \\
(n=8) \\
\text { Mean (SD) }\end{array}$ & $p^{b}$ \\
\hline Knowledge progress & & & & & & \\
\hline Totally & $3.2(3.03)$ & $1.3(5.3)$ & 0.1 & $3.4(5.6)$ & $2.25(3.7)$ & 1 \\
\hline About disease & $1.5(2.4)$ & $-0.2(2.7)$ & 0.006 & $1.8(2.5)$ & $0.5(1.4)$ & 0.19 \\
\hline About diet & $-1.1(3.5)$ & 1.1(3.1) & 0.92 & $1.6(3.9)$ & $2(1.7)$ & 0.45 \\
\hline About medications & $0.5(1.5)$ & $-0.1(2.01)$ & 0.37 & $0.1(0.99)$ & $0.25(1.8)$ & 0.75 \\
\hline About health attitude & $0.11(1.2)$ & $0.1(1.3)$ & 0.91 & $-0.1(1.5)$ & $-0.5(1.3)$ & 0.59 \\
\hline
\end{tabular}




\begin{tabular}{|c|c|c|c|c|c|c|}
\hline & \multicolumn{3}{|c|}{ ITT analysis } & \multicolumn{3}{|c|}{ PP analysis } \\
\hline & $\begin{array}{c}\text { Study } \\
(n=10) \\
\text { Mean (SD) }\end{array}$ & $\begin{array}{c}\text { Control } \\
(n=20) \\
\text { Mean (SD) }\end{array}$ & $p^{a}$ & $\begin{array}{c}\text { Study } \\
(n=9) \\
\text { Mean (SD) }\end{array}$ & $\begin{array}{c}\text { Control } \\
(n=8) \\
\text { Mean (SD) }\end{array}$ & $p^{b}$ \\
\hline Knowledge* & & & & & & \\
\hline Before the PC & $17.3(3.3)$ & 18.1(4.3) & 0.51 & $15.0(3.4)$ & $20.4(4.2)$ & 0.02 \\
\hline After the PC & $22.9(3.4)$ & $20.1(2.33)$ & 0.03 & $22.3(2.6)$ & $20.1(4.3)$ & 0.20 \\
\hline Difference & $4.44(1.9)$ & $-0.3(1.9)$ & 0.11 & $7.3(4.0)$ & $-0.3(1.9)$ & 0.001 \\
\hline Satisfaction** & & & & & & \\
\hline Before the PC & $2.4(2.7)$ & $3.3(2.2)$ & 0.07 & $1.9(2.0)$ & $3.4(1.4)$ & 0.10 \\
\hline After the PC & $2.7(2.4)$ & $1.5(3.6)$ & 0.3 & $2.6(3.4)$ & 1.1(4.1) & 0.41 \\
\hline Difference & $1.1(3.4)$ & $-1.8(3.7)$ & 0.04 & $0.7(4.5)$ & $-2.3(3.7)$ & 0.15 \\
\hline
\end{tabular}

and only $55 \%$ patients in the control group. However we do not know whether it is due to increased number of medications used by patient in study group or due to education on lifestyle provided by pharmacists.

Our study demonstrated that pharmaceutical care also had positive effect on patient's knowledge about disease. Improvement in the patient's knowledge may have a positive effect on their health behaviors and may result to better level of the patient health. ${ }^{27}$

No significant difference in the quality of life was demonstrated between the study and the control group after the end of the program. In other studies, not only positive effect of the pharmaceutical care on quality of life ${ }^{28}$ was demonstrated but also lack of positive impact was described. ${ }^{10,29}$

Pharmaceutical care requires appropriate education of the pharmacist. During pharmaceutical care, the pharmacist has a chance to improve his/her knowledge and skills. ${ }^{30}$ In Poland, the evaluation of the impact of the pharmaceutical care on pharmacists' knowledge and satisfaction was carried out for the first time. It was demonstrated that expanding professional activity of pharmacists had beneficial effect on their professional satisfaction. Before beginning the study, pharmacists randomized to study group demonstrated significantly lower professional satisfaction than pharmacists in control group. At the end of the study, the job satisfaction was similar for pharmacists from both groups. In addition, there was a significant increase in satisfaction level in pharmacists conducting pharmaceutical care compared to the control group in which almost double decrease in the work satisfaction occurred. Moreover, studies done all over the world have demonstrated that work with patient increases pharmacist satisfaction. ${ }^{31,32}$

A small number of patients were covered by the whole program of pharmaceutical care, which prevented the researchers from making conclusions about effectiveness of such type of actions in Polish population. However, the obtained results were a point of reference for further actions in relation to implementation of pharmaceutical care in Poland and its effectiveness assessment.

\section{CONCLUSIONS}

More patients who received pharmaceutical care had controlled blood pressure as compared to the group of patients using standard pharmaceutical services. The pharmaceutical care also had positive effect on the patients' knowledge about disease. Moreover, pharmacists, who provide pharmaceutical care improved their pharmacotherapy knowledge and had better satisfaction from their work.

\section{CONFLICT OF INTEREST}

There are no conflicts of interest to be disclosed.

This research received no specific grant from any funding agency in the public, commercial, or not-forprofit sectors.

\section{References}

1. Borzecki AM, Oliveria SA, Berlowitz DR. Barriers to hypertension control. Am Heart J. 2005;149(5):785-794.

2. Berlowitz DR, Ash AS, Hickey EC, Friedman RH, Glickman M, Kader B, Moskowitz MA. Inadequate management of blood pressure in a hypertensive population. N Engl J Med. 1998;339(27):1957-1963.

3. Degli Esposti E, Di Martino M, Sturani A, Russo P, Dradi C, Falcinelli S, Buda S. Risk factors for uncontrolled hypertension in Italy. J Hum Hypertens. 2004;18(3):207-213.

4. Jokisalo E, Kumpusalo E, Enlund H, Takala J. Patients' perceived problems with hypertension and attitudes towards medical treatment. J Hum Hypertens. 2001;15(11):755-761.

5. Hedner T, Oparil S, Narkiewicz K, Kjeldsen SE. Achieving better blood pressure control. Blood Press Suppl. 2008;1:3-4.

6. Harmon G, Lefante J, Krousel-Wood M. Overcoming barriers: the role of providers in improving patient adherence to antihypertensive medications. Curr Opin Cardiol. 2006;21(4):310-315

7. Bogden PE, Abbott RD, Williamson $P$, Onopa JK, Koontz LM. Comparing standard care with a physician and pharmacist team approach for uncontrolled hypertension. J Gen Intern Med. 1998;13(11):740-745. 
8. Cuspidi C, Meani S, Fusi V, Salerno M, Valerio C, Severgnini B, Catini E, Leonetti G, Magrini F, Zanchetti A. Home blood pressure measurement and its relationship with blood pressure control in a large selected hypertensive population. J Hum Hypertens. 2004;18(10):725-731.

9. Jones DW, Peterson ED. Improving hypertension control rates: technology, people, or systems? JAMA. 2008;299(24):2896-2898.

10. Hunt JS, Siemienczuk J, Pape G, Rozenfeld Y, MacKay J, LeBlanc BH, Touchette D. A randomized controlled trial of team-based care: impact of physician-pharmacist collaboration on uncontrolled hypertension. J Gen Intern Med. 2008;23(12):1966-1972

11. Von Muenster SJ, Carter BL, Weber CA, Ernst ME, Milchak JL, Steffensmeier JJ, Xu Y. Description of pharmacist interventions during physician-pharmacist co-management of hypertension. Pharm World Sci. 2008;30(1):128-135.

12. McLean DL, McAlister FA, Johnson JA, King KM, Makowsky MJ, Jones CA, Tsuyuki RT. A randomized trial of the effect of community pharmacist and nurse care on improving blood pressure management in patients with diabetes mellitus: study of cardiovascular risk intervention by pharmacists-hypertension (SCRIP-HTN). Arch Intern Med. 2008;168(21):2355-2361.

13. Chabot I, Moisan J, Gregoire JP, Milot A. Pharmacist intervention program for control of hypertension. Ann Pharmacother. 2003;37(9):1186-1193.

14. Cote I, Moisan J, Chabot I, Gregoire JP. Health-related quality of life in hypertension: impact of a pharmacy intervention program. J Clin Pharm Ther. 2005;30(4):355-362.

15. Green BB, Cook AJ, Ralston JD, Fishman PA, Catz SL, Carlson J, Carrell D, Tyll L, Larson EB, Thompson RS. Effectiveness of home blood pressure monitoring, Web communication, and pharmacist care on hypertension control: a randomized controlled trial. JAMA 2008;299(24):2857-2867.

16. Green BB, Ralston JD, Fishman PA, Catz SL, Cook A, Carlson J, Tyll L, Carrell D, Thompson RS. Electronic communications and home blood pressure monitoring (e-BP) study: design, delivery, and evaluation framework. Contemp Clin Trials. 2008;29(3):376-395.

17. Erhun WO, Agbani EO, Bolaji EE. Positive benefits of a pharmacist-managed hypertension clinic in Nigeria. Public Health. 2005;119(9):792-798.

18. Mehos BM, Saseen JJ, MacLaughlin EJ. Effect of pharmacist intervention and initiation of home blood pressure monitoring in patients with uncontrolled hypertension. Pharmacotherapy 2000;20(11):1384-1389.

19. McConnell KJ, Zadvorny EB, Hardy AM, Delate T, Rasmussen JR, Merenich JA. Coronary artery disease and hypertension: outcomes of a pharmacist-managed blood pressure program. Pharmacotherapy. 2006;26(9):1333-1341.

20. Reid F, Murray P, Storrie M. Implementation of a pharmacist-led clinic for hypertensive patients in primary care--a pilot study. Pharm World Sci. 2005;27(3):202-207.

21. Aguwa CN, Ukwe CV, Ekwunife Ol. Effect of pharmaceutical care program on blood pressure and quality of life in a Nigerian pharmacy. Pharm World Sci. 2008;30(1):107-110.

22. Zillich AJ, Sutherland JM, Kumbera PA, Carter BL. Hypertension outcomes through blood pressure monitoring and evaluation by pharmacists (HOME study). J Gen Intern Med. 2005;20(12):1091-1096.

23. Hepler Ch., Strand L. Opportunities and responsibilities in pharmaceutical care. Am J Hosp Pharm 1990;47:533-554

24. Ware JE., Sherbourne CD. The MOS 36-item short-form Health Survey (SF-36): I. Conceptual Framework and Item Selection, Med Care. 1992;30(6):473-483

25. Ware JE, Kosinski M, Dewey JE. How to score Version 2 of the SF-36 Health Survey (Standard \& Acute Forms). Lincoln, TI: QualityMetric Incorporated, 2000

26. Mancia G, De Backer G, Dominiczak A, Cifkova R, Fagard R, Germano G, Grassi G, Heagerty AM, Kjeldsen SE, Laurent S, Narkiewicz K, Ruilope L, Rynkiewicz A, Schmieder RE, Boudier HA, Zanchetti A; ESH-ESC Task Force on the Management of Arterial Hypertension. 2007 ESH-ESC Practice Guidelines for the Management of Arterial Hypertension: ESH-ESC Task Force on the Management of Arterial Hypertension. J Hypertens. 2007;25(9):1751-1762

27. Morisky DE, Levine DM, Green LW, Shapiro S, Russell RP, Smith CR. Five-year blood pressure control and mortality following health education for hypertensive patients. Am J Public Health. 1983;73(2):153-162.

28. Carter BL, Barnette DJ, Chrischilles E, Mazzotti GJ, Asali ZJ. Evaluation of hypertensive patients after care provided by community pharmacists in a rural setting. Pharmacotherapy. 1997;17(6):1274-1285.

29. Erickson SR, Slaughter R, Halapy H. Pharmacists' ability to influence outcomes of hypertension therapy. Pharmacotherapy. 1997;17(1):140-147.

30. Villeneuve J, Lamarre D, Lussier MT, Vanier MC, Genest J, Blais L, Hudon E, Perreault S, Berbiche D, Lalonde L. Physician-pharmacist collaborative care for dyslipidemia patients: knowledge and skills of community pharmacists. $\mathrm{J}$ Contin Educ Health Prof. 2009;29(4):201-208.

31. Collins C, Kramer A, O'Day ME, Low MB. Evaluation of patient and provider satisfaction with a pharmacist-managed lipid clinic in a Veterans Affairs medical center. Am J Health Syst Pharm. 2006;63(18):1723-1727.

32. Lapane KL, Hughes CM. Baseline job satisfaction and stress among pharmacists and pharmacy technicians participating in the Fleetwood Phase III Study. Consult Pharm. 2004;19(11):1029-1037. 